\title{
Study Protocol Version Mandatory Indicator
}

National Cancer Institute

\section{Source}

National Cancer Institute. Study Protocol Version Mandatory Indicator. NCI Thesaurus.

Code C94114.

Specifies whether the modifications contained in the study protocol version must be applied to all sites and subjects that want to continue participating in the study. 